\title{
Economic burden of peanut allergy in pediatric patients with evidence of reactions to peanuts in the United States
}

\author{
Michael S Blaiss, MD, FACAAl; J Allen Meadows, MD; Shengsheng Yu, PhD; Dan R Robison, MBA; Steve L Hass, PhD; \\ Kevin E Norrett, MS, MBA; Annie Guerin, MSc; Dominick Latremouille-Viau, MSc; and Stephen A Tilles, MD
}

\section{What is already known about this subject}

- Until recently, there were no approved therapies for peanut allergy.

- Although the economic burden of food allergy is large, costs specific to patients with peanut allergy experiencing reactions to peanuts remain to be evaluated.

\section{What this study adds}

- In the United States, privately insured and Medicaid-insured pediatric patients with peanut allergy and evidence of reactions triggering medical services have significantly higher comorbidity burdens (including depression and asthma) and economic burdens, regardless of asthma-related costs.

- Until recently, allergen avoidance was the only option to mitigate allergic reactions following accidental exposure to peanuts; therefore, a better understanding of cost of care associated with peanut allergen avoidance was warranted.

\section{Author affiliations}

Michael S Blaiss, MD, FACAAI, Medical College of Georgia at Augusta University, Roswell, GA; J Allen Meadows, MD, Alabama College of Osteopathic Medicine, Montgomery; and Steve L Hass, PhD, H. E. Outcomes, Los Angeles, CA. Shengsheng Yu, PhD; Dan R Robison, MBA; Kevin E Norrett, MS, MBA; and Stephen A Tilles, MD, Aimmune Therapeutics, a Nestlé Health Science company, Brisbane, CA. Annie Guerin, MSc, and Dominick LatremouilleViau, MSc, Analysis Group, Montreal, Quebec, Canada.

\section{AUTHOR CORRESPONDENCE:}

Dominick Latremouille-Viau, 514.394.4431; dominick.latremouille-viau@analysisgroup.com

J Manag Care Spec Pharm 2021;27(4):516-27

Copyright $(2020$, Academy of Managed Care Pharmacy. All rights reserved.

and depression, $\mathrm{HRU}$, and direct health care costs were compared between cohorts and reported for both perspectives separately.

RESULTS: Compared with peanut allergyfree patients ( $n=30,840$ privately insured; $\mathrm{n}=12,450$ Medicaid), peanut allergy patients ( $n=3,084$ privately insured; $n=1,245$ Medicaid) had higher prevalence of asthma, atopic dermatitis/eczema, other food allergies, allergic rhinitis, depression, and anxiety (all $P<0.01$ ). Peanut allergy patients had higher HRU per patient per year (PPPY), including $90 \%$ more emergency department 
visits among both privately insured and Medicaid patients $(P<0.01)$ and higher direct health care costs PPPY, with incremental costs of $\$ 2,247$ total or $\$ 1,712$ excluding asthma-related costs for privately insured patients and $\$ 2,845$ total or $\$ 1,844$ excluding asthma-related costs for Medicaid patients (all $P<0.01$ ).

CONCLUSIONS: Pediatric patients in the United States with peanut allergy and reactions triggering HRU had significantly higher comorbidity burdens, HRU, and direct health care costs, regardless of asthma-related costs, versus those without peanut allergy.

The onset of peanut allergy occurs most often during childhood, and unlike other food allergies, peanut allergy typically persists into adulthood. ${ }^{1}$ The childhood prevalence of peanut allergy in the United States ranges from $1.2 \%$ to $2.2 \%{ }^{2-5}$ and has been seen to increase over time. ${ }^{5}$

Approximately $12 \%$ of children with peanut allergy suffer from recurrent, potentially life-threatening allergic reactions annually, ${ }^{6}$ and peanut-induced anaphylaxis (i.e., life-threatening systemic hypersensitivity reaction) is increasing in incidence. ${ }^{7-9}$ Accordingly, the rate of emergency department (ED) visits for food-related anaphylaxis has also been increasing, ${ }^{10,11}$ albeit without a concomitant increase in deaths..$^{12}$

Despite the risk of severe peanut anaphylaxis,$^{13}$ there is currently no established classification system for peanut allergy severity. ${ }^{1}$ Over the course of this study, on January 31, 2020, the U.S. Food and Drug Administration (FDA) approved peanut (Arachis hypogaea) allergen powder-dnfp (PTAH; previously known as AR101), the first oral immunotherapy indicated for the mitigation of allergic reactions, including anaphylaxis, that may occur with accidental exposure to peanuts, when used in conjunction with a peanut-avoidant diet. ${ }^{14}$ Therefore, until recently, patients with peanut allergy had no other FDA-approved preventative options beyond allergen avoidance and treatment of an allergic reaction due to accidental ingestion/exposure with antihistamines, epinephrine autoinjector, and/or a visit to the ED.1,15 Consequently, the stress of extreme dietary vigilance and constant uncertainty may substantially diminish quality of life and increase psychological distress for patients with peanut allergy and their families. ${ }^{16,17}$ Further adding to the disease burden are the comorbidities frequently associated with food and/or peanut allergy, including atopic dermatitis/eczema, ${ }^{18}$ other food allergies, ${ }^{3}$ allergic rhinitis, ${ }^{18}$ mental health issues, ${ }^{19-21}$ and asthma, of which acute exacerbations are a particularly important problem in patients with concomitant peanut allergy. . $^{18,22,23}$
Accordingly, the economic burden of food allergy is large. ${ }^{24-28}$ The overall cost of childhood food allergy in the United States was estimated at $\$ 24.8$ billion annually in 2011, with inpatient (IP), outpatient (OP), and ED visits being the main cost drivers. ${ }^{25}$ One recent study by Shaker et al. (2010) on peanut allergy in the United States showed high health care resource utilization (HRU) in commercially insured patients. ${ }^{29}$ However, the study did not assess the long-term costs associated with peanut allergy beyond 1 year from diagnosis. Additionally, it is evident that despite the practice of peanut avoidance, accidental exposure is common ${ }^{30}$ highlighting the current unmet treatment needs in these young patients, who may also be insured through other types of health plans, namely those enrolled in the public Medicaid program. ${ }^{31}$ Thus, a more comprehensive understanding of the specific cost of care associated with peanut allergy is warranted, particularly among pediatric patients with evidence of reactions to peanuts for whom allergen avoidance alone is not sufficient.

This retrospective, claims-based, matched-cohort study assessed the economic burdens related to peanut allergy among privately insured and Medicaid-insured pediatric patients with evidence of reaction to peanuts in the United States, taking into account the HRU and costs associated with comorbidities frequently associated with peanut allergy such as asthma. ${ }^{18,22,23}$

\section{Methods}

\section{DATA SOURCE}

The Optum Health Care Solutions database (privately insured patients) and Medicaid Claims Database (Medicaid patients from Iowa, Kansas, Mississippi, Missouri, New Jersey, and Wisconsin) from 2007 to 2017 were used (see Additional Methods in the supplementary materials, available in online article).

\section{STUDY DESIGN AND SAMPLE SELECTION}

A retrospective matched-cohort design using administrative claims data was used. Patients aged 4-17 years were classified into 2 mutually exclusive cohorts: (a) peanut allergy cohort and (b) peanut allergy-free cohort (Supplementary Figures 1 and 2, available in online article). Patients in the peanut allergy cohort were required to have peanut allergy (i.e., medical service claims with an International Classification of Diseases, Ninth/Tenth Revision, Clinical Modification [ICD-9/10-CM] diagnosis of peanut allergy or a diagnosis of anaphylactic reaction due to peanuts: 995.61, V15.01, T78.01xx, or Z91.010) and evidence of reactions to peanuts resulting in HRU via 2 criteria: (a) patients coded 
with a diagnosis of anaphylactic reaction due to peanuts or (b) patients coded with a diagnosis of peanut allergy and an indicator of allergic reactions during the same medical service. Indicators of allergic reactions included an ED visit with a diagnosis of peanut allergy, a diagnosis of anaphylactic reaction due to unspecified food with a diagnosis of peanut allergy, or a diagnosis related to symptoms of reaction to peanuts with a diagnosis of peanut allergy (Supplementary Table 1, available in online article). Patients in the peanut allergy-free cohort were required to have no coded diagnoses of peanut allergy or anaphylactic reaction due to peanuts at any time during the study.

Patients in the peanut allergy cohort were matched 1:10 to patients in the peanut allergy-free cohort based on age, sex, region/state of residence, type of health plan, race (Medicaid patients), and calendar year of index date, all of which were measured as of the index date.

For patients in the peanut allergy cohort, the index date was the date with the first evidence of reaction to peanuts resulting in medical service use or a prescription of epinephrine autoinjector in pharmacy claims. For patients in the peanut allergy-free cohort, the index date was set to the same date of the matched patient from the peanut allergy cohort. As a code-based claims study, all patients were required to have continuous health plan coverage for $\geq 12$ months following the index date to ensure sufficient data were available to allow a comprehensive understanding of the annual economic burden in this population. The duration of the study period varied by patient and spanned from the index date until the end of data or end of continuous health plan coverage, whichever occurred first, in order to use all available data.

\section{STUDY OUTCOMES}

Study outcomes measured during the study period included comorbidities, HRU, and direct health care costs.

Comorbidities frequently associated with peanut allergy in the literature were identified in medical claims with a diagnosis of asthma, ${ }^{18,22,23}$ atopic dermatitis/eczema, ${ }^{18}$ multiple food allergies (other than peanut allergy), ${ }^{3}$ allergic rhinitis, ${ }^{18}$ depression, ${ }^{19}$ or anxiety ${ }^{19,20}$ and reported as prevalence (see Additional Methods in the supplementary materials, available in online article). Quan-Charlson Comorbidity Index (Quan-CCI) was reported for both cohorts.

HRU was reported as annual incidence rates and included IP admissions and days, ED visits, days with OP services, and prescription fills for epinephrine autoinjector.

All-cause total direct health care costs were reported per patient per year (PPPY) in 2017 USD from a payer's perspective (paid amounts) and included all-cause medical service costs (IP, ED, and OP costs) and pharmacy costs (including costs for epinephrine autoinjector). Medical and pharmacy costs associated with each of asthma, atopic dermatitis/eczema, other food allergy, and mental health were also measured (not mutually exclusive; Additional Methods in the supplementary material). To further characterize the source of pharmacy costs, the most frequently prescribed drugs (excluding epinephrine) based on Generic Product Identifier were identified for patients in the peanut allergy cohort. Additionally, patient total out-of-pocket health care expenses (i.e., deductible, coinsurance, and copay) were reported for privately insured patients.

Considering the association between asthma and peanut allergy and important HRU and costs associated with asthma, a sensitivity analysis was performed to exclude asthma-related HRU and costs from the annual incidence rates and total all-cause health care costs, respectively.

\section{STATISTICAL ANALYSIS}

Patient characteristics were summarized using descriptive statistics and presented separately for the peanut allergy cohort and peanut allergy-free cohort after matching. Standardized differences between the 2 cohorts of $\geq|0.2|$ suggested imbalance..$^{32-34}$

Comorbidities frequently associated with peanut allergy were compared between the matched cohorts using McNemar tests and Bonferroni correction to account for multiple comparisons.

HRU events were compared by category between the matched cohorts using generalized linear models with a Poisson distribution, with P values and 95\% CIs estimated using a nonparametric bootstrap technique. Results were reported as an incidence rate ratio (IRR).

Incremental direct health care costs associated with peanut allergy were estimated by comparing costs incurred by the matched cohorts using weighted 2-part models. $P$ values were estimated using a nonparametric bootstrap technique.

\section{Results}

\section{PATIENT CHARACTERISTICS}

Among privately insured patients, $52.5 \%$ of those diagnosed with peanut allergy had evidence of reactions to peanuts resulting in HRU (Supplementary Figure 1, available in online article). After sample selection, 6,971 patients in the peanut allergy cohort were matched to 69,710 patients in the peanut allergy-free cohort, of which 3,084 and 30,840 patients, respectively, were between the ages of 4 and 17 . Among patients aged $4-17$ years, the mean age was 8.3 years, 
TABLE 1 Demographic and Clinical Characteristics Among Privately Insured and Medicaid Pediatric Patients

\begin{tabular}{|c|c|c|c|c|c|c|c|c|}
\hline \multirow{4}{*}{$\begin{array}{l}\text { Patient Characteristics }^{\mathbf{a}} \\
\text { Age as of the index date, mean } \pm \text { SD (median), y } \\
\text { Male, } n(\%)\end{array}$} & \multicolumn{4}{|c|}{ Privately Insured } & \multicolumn{4}{|c|}{ Medicaid } \\
\hline & \multirow{2}{*}{\multicolumn{2}{|c|}{$\begin{array}{c}\begin{array}{c}\text { Peanut Allergy } \\
\text { Cohort } \\
\mathbf{n = 3 , 0 8 4}\end{array} \\
8.3 \pm 3.6(7.0) \\
\end{array}$}} & \multicolumn{2}{|c|}{$\begin{array}{c}\text { Peanut Allergy- } \\
\text { Free Cohort } \\
n=30,840\end{array}$} & \multicolumn{2}{|c|}{$\begin{array}{c}\text { Peanut Allergy } \\
\text { Cohort } \\
n=1,245\end{array}$} & \multicolumn{2}{|c|}{$\begin{array}{c}\text { Peanut Allergy- } \\
\text { Free Cohort } \\
n=12,450\end{array}$} \\
\hline & & & $8.3 \pm 3$ & $6(7.0)$ & $7.9 \pm 3$ & $7(7.0)$ & $7.9 \pm 3$ & $7(7.0)$ \\
\hline & 1,839 & $(59.6)$ & 18,390 & $(59.6)$ & 703 & $(56.5)$ & 7,030 & $(56.5)$ \\
\hline \multicolumn{9}{|l|}{ Race, ${ }^{a}$ n (\%) } \\
\hline White & \multicolumn{2}{|c|}{-} & \multicolumn{2}{|c|}{-} & 467 & $(37.5)$ & 4,670 & $(37.5)$ \\
\hline Black & \multicolumn{2}{|c|}{-} & \multicolumn{2}{|c|}{-} & 523 & $(42.0)$ & 5,230 & $(42.0)$ \\
\hline \multicolumn{9}{|l|}{ Region of residence, ${ }^{\mathrm{b}} \mathrm{n}(\%)$} \\
\hline Northeast & 1,104 & $(35.8)$ & 11,040 & $(35.8)$ & \multicolumn{2}{|c|}{ - } & \multicolumn{2}{|c|}{-} \\
\hline South & 793 & $(25.7)$ & 7,930 & $(25.7)$ & \multicolumn{2}{|c|}{-} & \multicolumn{2}{|c|}{-} \\
\hline West & 560 & $(18.2)$ & 5,600 & $(18.2)$ & \multicolumn{2}{|c|}{-} & \multicolumn{2}{|c|}{-} \\
\hline Midwest & 513 & $(16.6)$ & 5,130 & $(16.6)$ & \multicolumn{2}{|c|}{-} & \multicolumn{2}{|c|}{-} \\
\hline \multicolumn{9}{|l|}{ State of residence, $\mathrm{n}(\%)$} \\
\hline lowa & \multicolumn{2}{|c|}{-} & \multicolumn{2}{|c|}{-} & 271 & $(21.8)$ & 2,710 & $(21.8)$ \\
\hline Kansas & \multicolumn{2}{|c|}{-} & \multicolumn{2}{|c|}{ - } & 103 & (8.3) & 1,030 & $(8.3)$ \\
\hline Mississippi & \multicolumn{2}{|c|}{ - } & \multicolumn{2}{|c|}{-} & 411 & $(33.0)$ & 4,110 & $(33.0)$ \\
\hline Missouri & \multicolumn{2}{|c|}{ - } & \multicolumn{2}{|c|}{ - } & 182 & $(14.6)$ & 1,820 & $(14.6)$ \\
\hline New Jersey & \multicolumn{2}{|c|}{-} & \multicolumn{2}{|c|}{-} & 235 & $(18.9)$ & 2,350 & $(18.9)$ \\
\hline Wisconsin & \multicolumn{2}{|c|}{-} & & & 43 & (3.5) & 430 & (3.5) \\
\hline Health plan type, ${ }^{b}$ n (\%) & & & & & & & & \\
\hline PPO & 1,971 & $(63.9)$ & 19,710 & $(63.9)$ & & & - & \\
\hline POS & 437 & $(14.2)$ & 4,370 & $(14.2)$ & & & - & - \\
\hline $\mathrm{HMO}$ & 289 & $(9.4)$ & 2,890 & $(9.4)$ & 421 & $(33.8)$ & 4,210 & $(33.8)$ \\
\hline Non-HMO & & & & & 824 & $(66.2)$ & 8,240 & $(66.2)$ \\
\hline
\end{tabular}

continued on next page

and $59.6 \%$ were male in both cohorts (Table 1 ). The mean length of the study period was 4.5 years for the peanut allergy cohort and 4.1 years for the peanut allergy-free cohort (standardized difference $=0.17$ ).

Among Medicaid patients, $40.3 \%$ of those diagnosed with peanut allergy had evidence of reactions to peanuts resulting in HRU (Supplementary Figure 2, available in online article). After sample selection, 2,799 patients in the peanut allergy cohort were matched to 27,990 patients in the peanut allergy-free cohort, of which 1,245 and 12,450 patients, respectively, were between the ages of 4 and 17 . Among patients aged 4-17 years, the mean age was 7.9 years, and $56.5 \%$ were male in both cohorts (Table 1 ). The mean length of the study period was 4.0 years for the peanut allergy cohort and 4.2 years for the peanut allergy-free cohort (standardized difference $=0.08$ ).

\section{COMORBIDITY BURDEN}

The proportion of privately insured patients with comorbidities frequently associated with peanut allergy was higher among those in the peanut allergy cohort than those in the peanut allergy-free cohort, as evidenced by the prevalence of asthma ( $54.8 \%$ vs. $13.7 \%)$, atopic dermatitis/eczema (34.9\% vs. $13.3 \%)$, other food allergies ( $42.2 \%$ vs. $0.8 \%$ ), allergic rhinitis $(66.4 \%$ vs. $20.5 \%)$, depression (13.6\% vs. $9.7 \%)$, and anxiety (10.8\% vs. $7.5 \%)$, respectively (all P<0.01; Table 1). Privately insured patients in the peanut allergy cohort had a higher mean CCI score than those in the peanut allergy-free cohort $(0.6$ vs. 0.2 , respectively; $\mathrm{P}<0.01)$. A lower proportion of patients in the peanut allergy cohort had a CCI score of zero compared with patients in the peanut allergy-free cohort ( $43.5 \%$ vs. $82.9 \%$, respectively; $\mathrm{P}<0.01)$. 
TABLE 1 Demographic and Clinical Characteristics Among Privately Insured and Medicaid Pediatric Patients (continued)

\begin{tabular}{|c|c|c|c|c|c|c|c|c|}
\hline \multirow{2}{*}{$\begin{array}{l}\text { Patient Characteristics } \\
\text { Year of index date, } n(\%)\end{array}$} & \multicolumn{4}{|c|}{ Privately Insured } & \multicolumn{4}{|c|}{ Medicaid } \\
\hline & \multicolumn{2}{|c|}{$\begin{array}{c}\text { Peanut Allergy } \\
\text { Cohort } \\
n=3,084\end{array}$} & \multicolumn{2}{|c|}{$\begin{array}{c}\text { Peanut Allergy- } \\
\text { Free Cohort } \\
n=30,840\end{array}$} & \multicolumn{2}{|c|}{$\begin{array}{c}\text { Peanut Allergy } \\
\text { Cohort } \\
n=1,245\end{array}$} & \multicolumn{2}{|c|}{$\begin{array}{c}\text { Peanut Allergy- } \\
\text { Free Cohort } \\
n=12,450\end{array}$} \\
\hline 2007 & 496 & $(16.1)$ & 4,960 & $(16.1)$ & 69 & $(5.5)$ & 690 & $(5.5)$ \\
\hline 2008 & 307 & $(10.0)$ & 3,070 & $(10.0)$ & 84 & $(6.7)$ & 840 & $(6.7)$ \\
\hline 2009 & 430 & $(13.9)$ & 4,300 & (13.9) & 149 & $(12.0)$ & 1,490 & $(12.0)$ \\
\hline 2010 & 509 & $(16.5)$ & 5,090 & $(16.5)$ & 157 & $(12.6)$ & 1,570 & $(12.6)$ \\
\hline 2011 & 312 & $(10.1)$ & 3,120 & $(10.1)$ & 194 & $(15.6)$ & 1,940 & (15.6) \\
\hline 2012 & 323 & $(10.5)$ & 3,230 & $(10.5)$ & 179 & $(14.4)$ & 1,790 & (14.4) \\
\hline 2013 & 243 & (7.9) & 2,430 & (7.9) & 151 & (12.1) & 1,510 & (12.1) \\
\hline 2014 & 263 & $(8.5)$ & 2,630 & $(8.5)$ & 138 & $(11.1)$ & 1,380 & (11.1) \\
\hline 2015 & 173 & (5.6) & 1,730 & (5.6) & 101 & $(8.1)$ & 1,010 & $(8.1)$ \\
\hline 2016 & 28 & $(0.9)$ & 280 & $(0.9)$ & 23 & (1.8) & 230 & (1.8) \\
\hline Length of study period, months; median \pm SD (median) & $54.5 \pm 29$ & $5(49.2)$ & $49.4 \pm 28$ & $8(43.2)$ & $47.8 \pm 27$ & $3(41.9)$ & $49.9 \pm 26$ & $5(44.5)$ \\
\hline
\end{tabular}

Comorbidities frequently associated with peanut allergy during the study period, $\mathbf{n}(\%)^{\mathrm{c}}$

\begin{tabular}{|c|c|c|c|c|c|c|c|c|}
\hline Asthma & 1,690 & $(54.8)$ & 4,210 & $(13.7)$ & 777 & $(62.4)$ & 2,299 & $(18.5)$ \\
\hline Atopic dermatitis/eczema & 1,076 & $(34.9)$ & 4,106 & $(13.3)$ & 631 & $(50.7)$ & 2,220 & $(17.8)$ \\
\hline One or more specified food allergies (other than peanut) & 1,300 & $(42.2)$ & 247 & $(0.8)$ & 518 & (41.6) & 59 & $(0.5)$ \\
\hline Allergic rhinitis & 2,049 & $(66.4)$ & 6,320 & $(20.5)$ & 876 & $(70.4)$ & 3,321 & $(26.7)$ \\
\hline Depression & 420 & $(13.6)$ & 2,998 & $(9.7)$ & 192 & (15.4) & 1,730 & $(13.9)$ \\
\hline Anxiety & 332 & (10.8) & 2,309 & (7.5) & 104 & $(8.4)$ & 762 & $(6.1)$ \\
\hline
\end{tabular}

apatient characteristics were balanced, with a standardized difference of 0.00 for all covariates, except length of study period ( 0.17 for privately insured patients and 0.08 for Medicaid patients).

bonly the most prevalent categories were reported; unknown category was not reported.

'Comparisons between the peanut allergy and peanut allergy-free cohorts were statistically significant (all $P<0.01)$.

$H M O=$ health maintenance organization; $P O S=$ point of service; $P P O=$ preferred provider organization .

The proportion of Medicaid patients with comorbidities frequently associated with peanut allergy was also higher among those in the peanut allergy cohort than those in the peanut allergy-free cohort, as evidenced by the prevalence of asthma (62.4\% vs. 18.5\%), atopic dermatitis/eczema ( $50.7 \%$ vs. $17.8 \%)$, other food allergies ( $41.6 \%$ vs. $0.5 \%$ ), allergic rhinitis ( $70.4 \%$ vs. $26.7 \%)$, depression (15.4\% vs. $13.9 \%)$, and anxiety (8.4\% vs. $6.1 \%)$, respectively (all $\mathrm{P}<0.01$; Table 1$)$. Medicaid patients in the peanut allergy cohort had a higher mean CCI score than those in the peanut allergy-free cohort ( 0.7 vs. 0.3 , respectively; $\mathrm{P}<0.01$ ). A lower proportion of patients in the peanut allergy cohort had a CCI score of 0 compared with patients in the peanut allergy-free cohort (34.0\% vs. $76.2 \%$, respectively; $\mathrm{P}<0.01)$.

\section{HEALTH CARE RESOURCE UTILIZATION}

Privately insured patients in the peanut allergy cohort had higher HRU compared with those in the peanut allergyfree cohort, as evidenced by 0.04 versus 0.02 IP admissions PPPY, respectively (i.e., 65\% more in the peanut allergy cohort; IRR=1.65; $\mathrm{P}<0.01$; Figure $1 \mathrm{~A}$ ); 0.51 versus $0.27 \mathrm{ED}$ visits PPPY (i.e., 90\% more in the peanut allergy cohort; IRR $=1.90 ; P<0.01) ; 9.44$ versus 5.21 days with OP services PPPY (i.e., $81 \%$ more in the peanut allergy cohort; IRR $=1.81$; $\mathrm{P}<0.01$ ); and 1.31 versus 0.03 prescription fills for epinephrine autoinjector PPPY (i.e., $>50$ times more in the peanut allergy cohort; IRR $=50.42 ; \mathrm{P}<0.01)$. Results were consistent when excluding asthma-related HRU, with patients in the peanut allergy cohort having more IP admissions (IRR=1.31; 


\section{FIGURE 1 Comparison of HRU in Privately Insured Pediatric Patients and Medicaid Pediatric Patients}

A. Comparison of HRU in Privately Insured Pediatric Patients in the Peanut Allergy Cohort $(\mathbf{n}=3,084)$ versus Peanut Allergy-Free Cohort $(n=30,840)$

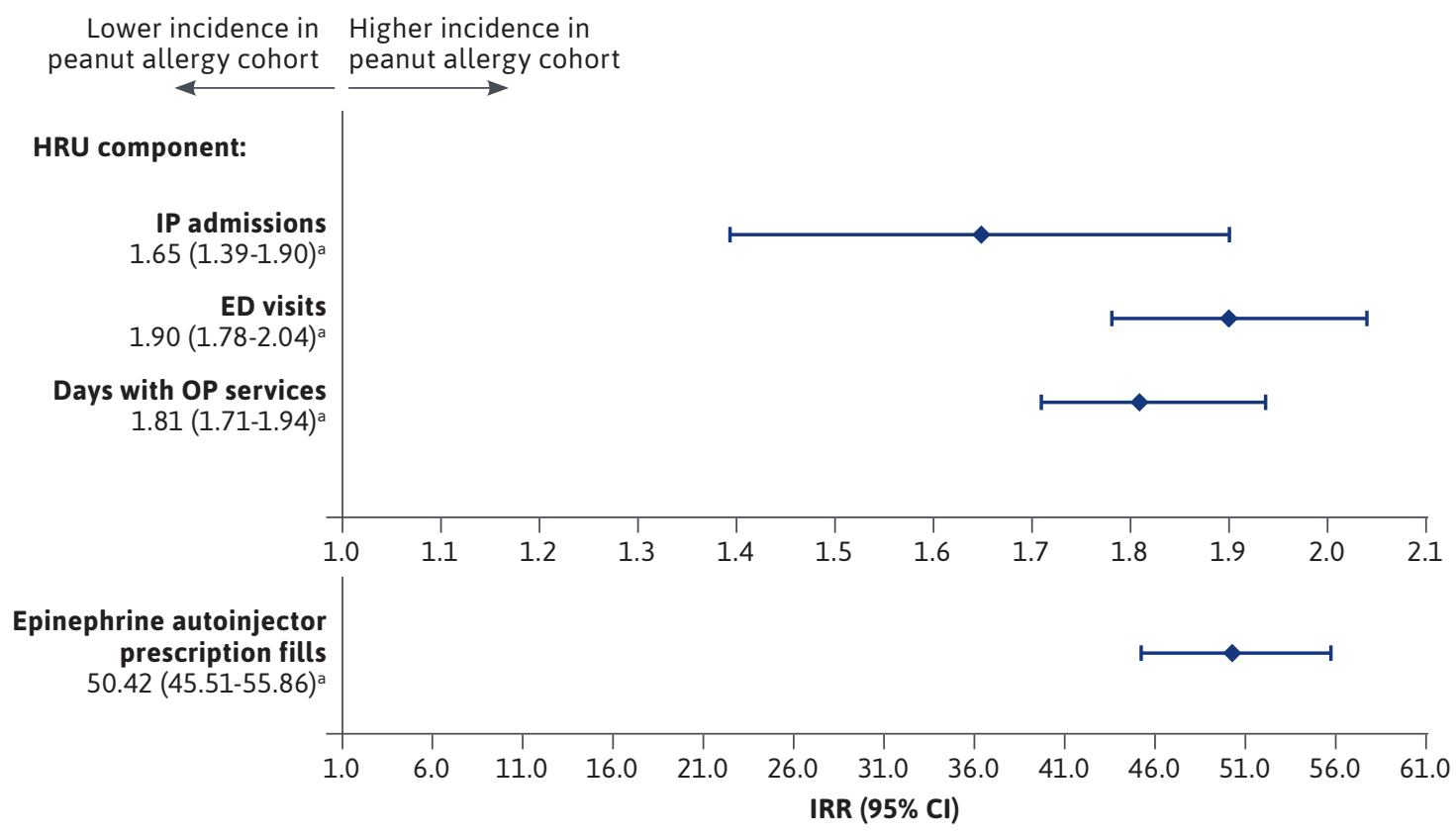

B. Comparison of HRU in Medicaid Pediatric Patients in the Peanut Allergy Cohort $(n=1,245)$ versus Peanut Allergy-Free Cohort $(n=12,450)$

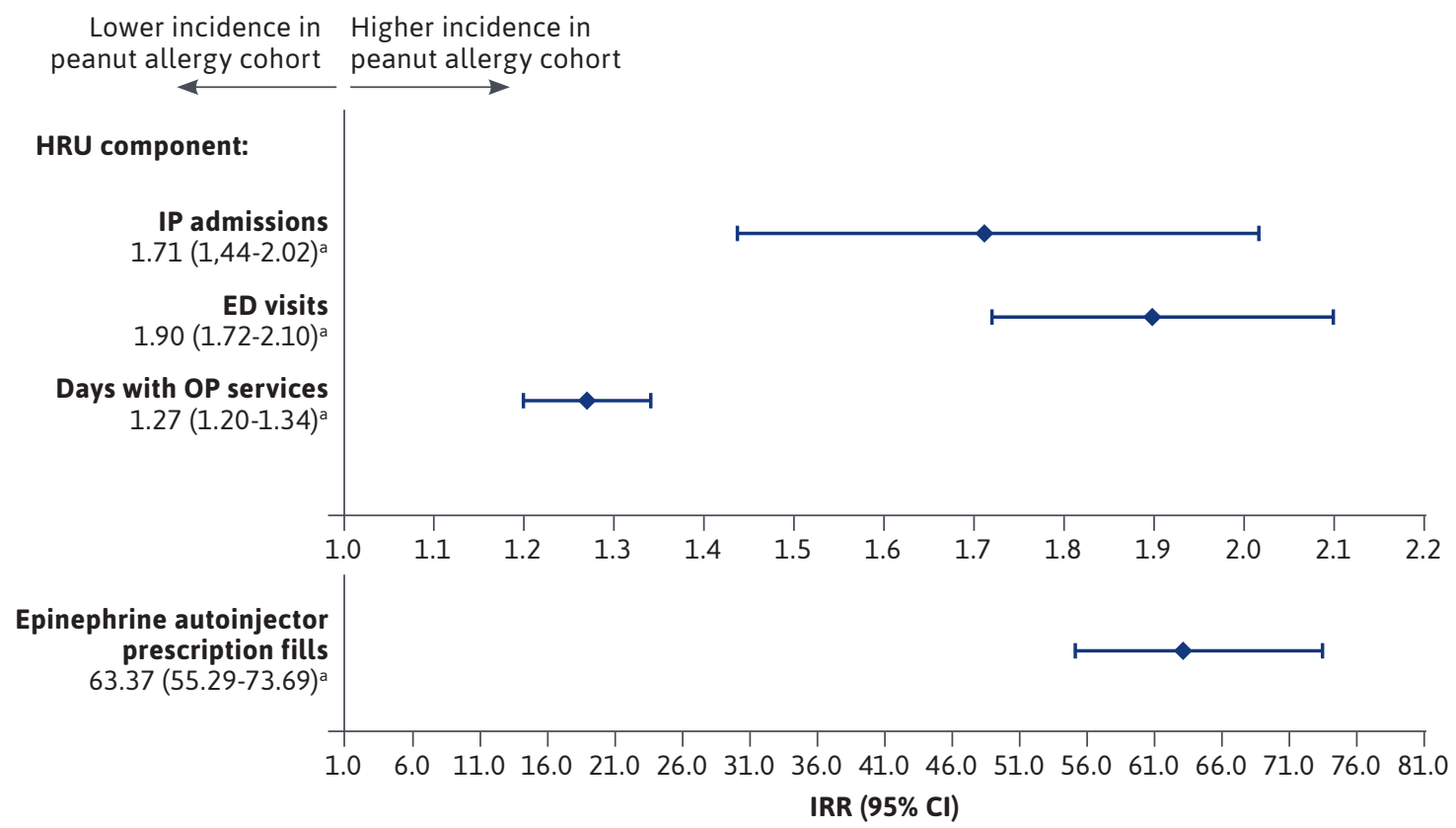

${ }^{a} P<0.01$.

$E D=$ emergency department; $H R U=$ health care resource utilization; $I P=$ inpatient; $I R R=$ incidence rate ratio; $O P=$ outpatient. 


\section{FIGURE 2 Comparison of Direct Health Care Costs in Privately Insured Pediatric Patients in the Peanut Allergy Cohort $(n=3,084)$ Versus Peanut Allergy-Free Cohort $(n=30,840)$ and in Medicaid Pediatric Patients in the Peanut Allergy Cohort $(n=1,245)$ Versus Peanut Allergy-Free Cohort $(n=12,450)$}

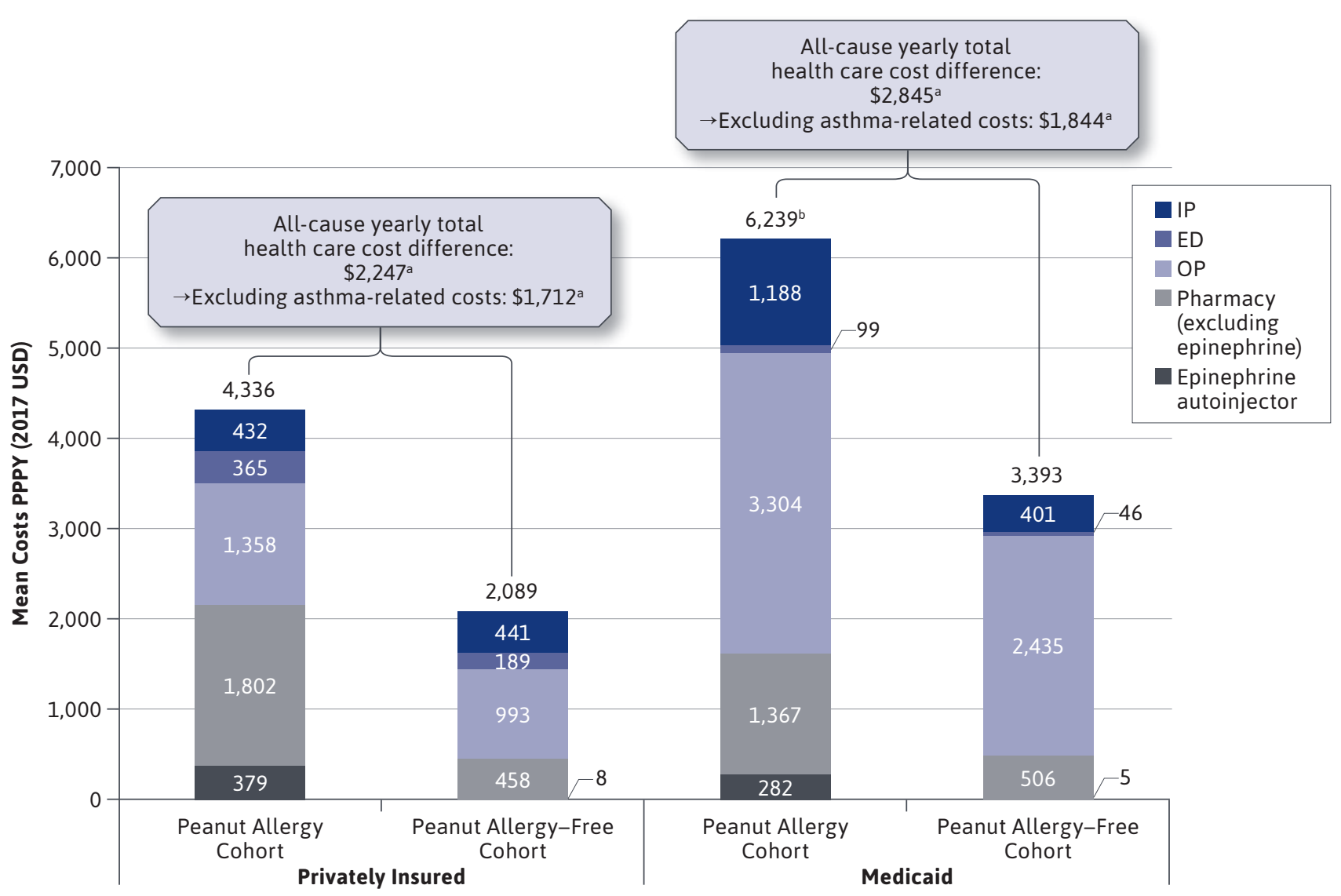

${ }^{a} P<0.01$.

${ }^{b}$ This cost does not equal the sum of the cost components due to rounding.

$E D=$ emergency department; IP =inpatient; $O P=$ outpatient; $P P P Y=$ per patient per year; USD=U.S. dollar.

$P=0.02)$; ED visits (IRR=1.81; $P<0.01)$; and days with OP services (IRR=1.71; $P<0.01$ ) PPPY compared with patients in the peanut allergy-free cohort (Supplementary Table 2, available in online article).

Medicaid patients in the peanut allergy cohort had higher HRU compared with those in the peanut allergy-free cohort, as evidenced by 0.55 versus 0.32 IP admissions PPPY, respectively (i.e., $71 \%$ more in the peanut allergy cohort; IRR=1.71; $P<0.01$; Figure 1B); 0.82 versus $0.43 \mathrm{ED}$ visits $P P P Y$ (i.e., $90 \%$ more in the peanut allergy cohort; IRR $=1.90$; $\mathrm{P}<0.01$ ); 20.01 versus 15.70 days with OP services PPPY (i.e., $27 \%$ more in the peanut allergy cohort; IRR=1.27; $P<0.01$ ); and 1.06 versus 0.02 prescription fills for epinephrine autoinjector PPPY (i.e., $>63$ times more in the peanut allergy cohort; IRR=63.37; $\mathrm{P}<0.01$ ). Results were consistent when excluding asthma-related HRU, with patients in the peanut allergy cohort having more IP admissions (IRR=1.27; $\mathrm{P}=0.03)$; ED visits $(\mathrm{IRR}=1.74 ; \mathrm{P}<0.01)$; and days with $\mathrm{OP}$ services $(\mathrm{IRR}=1.22 ; \mathrm{P}<0.01)$ PPPY compared with patients in the peanut allergy-free cohort (Supplementary Table 2, available in online article).

\section{HEALTH CARE COSTS}

Privately insured patients in the peanut allergy cohort incurred \$2,247 higher direct health care costs PPPY compared with patients in the peanut allergy-free cohort 


\section{TABLE 2 Comparison of Direct Health Care Costs Among Privately Insured and Medicaid Pediatric Patients During the Study Period}

\begin{tabular}{|c|c|c|c|c|c|c|}
\hline \multirow[b]{2}{*}{$\begin{array}{l}\text { Direct Health Care Costs } \\
\text { (2017 USD) }\end{array}$} & \multicolumn{2}{|c|}{ Privately Insured, mean PPPY \pm SD } & \multirow[b]{2}{*}{$\begin{array}{c}\text { Cost Difference } \\
(95 \% \mathrm{CI})\end{array}$} & \multicolumn{2}{|c|}{ Medicaid, mean PPPY \pm SD } & \multirow[b]{2}{*}{$\begin{array}{l}\text { Cost Difference } \\
(95 \% \mathrm{CI})\end{array}$} \\
\hline & $\begin{array}{c}\text { Peanut Allergy } \\
\text { Cohort } \\
n=3,084\end{array}$ & $\begin{array}{c}\text { Peanut Allergy- } \\
\text { Free Cohort } \\
n=30,840\end{array}$ & & $\begin{array}{c}\begin{array}{c}\text { Peanut Allergy } \\
\text { Cohort } \\
n=1,245\end{array} \\
\end{array}$ & $\begin{array}{c}\text { Peanut Allergy- } \\
\text { Free Cohort } \\
\mathbf{n}=12,450\end{array}$ & \\
\hline $\begin{array}{l}\text { All-cause total health } \\
\text { care costs }\end{array}$ & $4,336 \pm 29,273$ & $2,089 \pm 11,522$ & $2,247(1,195-3,936)^{a}$ & $6,239 \pm 13,988$ & $3,393 \pm 8,832$ & $2,845(2,086-3,728)^{\mathrm{a}}$ \\
\hline Asthma-related costs & $619 \pm 3,696$ & $84 \pm 903$ & $535 \quad(396-731)^{a}$ & $1,116 \pm 4,894$ & $114 \pm 1,026$ & $1,001 \quad(747-1,313)^{\mathrm{a}}$ \\
\hline $\begin{array}{l}\text { Atopic dermatitis/ } \\
\text { eczema-related costs }\end{array}$ & $60 \pm 443$ & $10 \pm 99$ & $50 \quad(34-76)^{\mathrm{a}}$ & $230 \pm 3,230$ & $17 \pm 223$ & $213 \quad(119-371)^{a}$ \\
\hline $\begin{array}{l}\text { Other food allergy- } \\
\text { related costs }\end{array}$ & $48 \pm 233$ & $1 \pm 38$ & $47 \quad(40-57)^{\mathrm{a}}$ & $127 \pm 1,729$ & $0 \pm 22$ & $(50-240)^{a}$ \\
\hline $\begin{array}{l}\text { Mental health-related } \\
\text { costs }\end{array}$ & $244 \pm 1,366$ & $224 \pm 1,710$ & $20 \quad(-37-87)$ & $1,156 \pm 6,338$ & $834 \pm 3,999$ & $322(-36-678)$ \\
\hline Medical service costs & $2,155 \pm 4,554$ & $1,624 \pm 10,533$ & $531 \quad(347-734)^{a}$ & $4,590 \pm 13,168$ & $2,882 \pm 8,333$ & $(993-2,552)^{a}$ \\
\hline Pharmacy costs & $2,181 \pm 28,840$ & $465 \pm 3,404$ & $1,716 \quad(746-3,289)^{a}$ & $1,649 \pm 3,320$ & $511 \pm 1,469$ & $(948-1,373)^{a}$ \\
\hline $\begin{array}{l}\text { Out-of-pocket all-cause } \\
\text { total health care costs }\end{array}$ & $962 \pm 3,284$ & $400 \pm 692$ & $562(448-735)^{a}$ & - & - & - \\
\hline
\end{tabular}

${ }^{a} P<0.01$

$P P P Y=$ per-patient per-year; $U S D=U . S$. dollars

$(\mathrm{P}<0.01$; Figure 2). Asthma-related costs, atopic dermatitis/eczema-related costs, other food allergy-related costs, and mental health-related costs accounted for $23.8 \%$, $2.2 \%, 2.1 \%$, and $0.9 \%$ of the cost difference, respectively (all $\mathrm{P}<0.01$ except for mental health-related costs; Table 2). Excluding asthma-related costs, patients in the peanut allergy cohort incurred $\$ 1,712$ higher costs PPPY compared with patients in the peanut allergy-free cohort $(P<0.01$; Figure 2). Additionally, patients in the peanut allergy cohort incurred \$562 higher out-of-pocket all-cause total health care costs PPPY compared with patients in the peanut allergy-free cohort $(\mathrm{P}<0.01)$. When combining patient outof-pocket and payers' contribution perspectives, the total incremental cost was of $\$ 2,809$ PPPY. Excluding epinephrine, the most frequently prescribed drugs to patients in the peanut allergy cohort were amoxicillin, albuterol, and azithromycin.

Medicaid patients in the peanut allergy cohort incurred $\$ 2,845$ higher direct health care costs PPPY compared with patients in the peanut allergy-free cohort $(P<0.01$; Figure 2). Asthma-related costs, atopic dermatitis/eczemarelated costs, other food allergy-related costs, and mental health-related costs accounted for $35.2 \%, 7.5 \%, 4.5 \%$, and $11.3 \%$ of the cost difference, respectively (all $\mathrm{P}<0.01$ except for mental health-related costs; Table 2). Excluding asthmarelated costs, patients in the peanut allergy cohort incurred
$\$ 1,844$ higher costs PPPY compared with patients in the peanut allergy-free cohort $(\mathrm{P}<0.01$; Figure 2$)$. Excluding epinephrine, the most frequently prescribed drugs to patients in the peanut allergy cohort were albuterol, amoxicillin, and prednisolone.

\section{Discussion}

This retrospective matched-cohort study assessed the cost of care associated with peanut allergy in privately insured and Medicaid-insured pediatric patients aged 4-17 years in the United States. Our results indicate that the comorbidity burden, HRU, and direct health care costs are significantly higher in pediatric patients with peanut allergy compared with those without peanut allergy, from both the private and public perspectives. Given the use of claims databases and the onset of peanut allergy largely during childhood, ${ }^{1}$ we targeted patients for whom the journey would reasonably include early or delayed introduction to peanuts, ${ }^{35}$ allergy testing, and early experience with food allergy avoidance to observe failure with reactions to peanuts resulting in HRU. In addition, as caregiver vigilance at a young age is likely to mitigate the risk of accidental exposure to peanuts, this study focuses on pediatric patients 4-17 years old with evidence of unmet treatment needs, a period when children and adolescents are being integrated into educational and 
social interactions and are developing the knowledge and skills needed to reduce their exposure risk.

As a claims-based study, reaction to peanuts could not be confirmed without clinical data, so patients were selected using HRU as a proxy. Approximately half of all patients diagnosed with peanut allergy had evidence of reactions to peanuts resulting in HRU at some point in data $(52.5 \%$ among privately insured patients; $40.3 \%$ among Medicaid patients). Accordingly, this study suggests that reactions to peanuts requiring medical attention are likely not uncommon for children with peanut allergy at the population level. Despite the practice of allergen avoidance, accidental exposure is common, ${ }^{30}$ with the resulting reaction being of variable and unpredictable severity. ${ }^{36}$ Indeed, in a study of children with confirmed peanut allergy, accidental exposure occurred at a rate of $12.4 \%$ per year, with $66 \%$ of the resulting reactions classified as moderate or severe. ${ }^{37}$ Taken together, this suggests that under food allergen avoidance alone without preventative therapy options, patients with peanut allergy are still at risk of allergic reactions warranting medical attention at any time.

Although most previous studies estimated costs associated with food allergy in general, ${ }^{24-27}$ an analysis of private insurance claims in the United States found that patients with a diagnosis of peanut allergy incurred medical service charges of \$237 PPPY, whereas patients diagnosed with anaphylactic reaction to peanuts incurred $\$ 429$ PPPY. ${ }^{28}$ These estimates are much lower than the costs reported in the present study, likely because the former study only included medical service costs associated with diagnosis claims and did not include pharmacy costs, ${ }^{28}$ which accounted for $25 \%-50 \%$ of the total health care costs in the present study. Our results were consistent with the recent study of Shaker et al. on cost observed in commercially insured pediatric patients of $\$ 2,247$ PPPY, which reported similarly high excess direct health care costs including patient out-ofpocket expenses during the first year of diagnosis, ranging from \$2,278 PPPY (aged 4-11 years) to \$4,340 PPPY (aged 12-18 years).$^{29}$ In this study, we also assessed the economic burden in the Medicaid-insured population, representing an important proportion of children with peanut allergy in the United States, ${ }^{31}$ showing incremental total health care costs of \$2,845 PPPY.

Regarding medical services, recent studies have shown that the rate of ED visits for food-related anaphylaxis is increasing ${ }^{10,11}$ and that the true frequency may be underestimated..$^{38}$ ED visits and IP hospitalizations have previously been identified as major components of medical costs associated with food allergy. ${ }^{25,39}$ Although patients with peanut allergy experienced high rates of ED visits in the present study, medical services were mainly driven by OP visits.
This is in line with other studies that have found similar HRU and cost allocations for food allergy in general. ${ }^{27,28}$ Regardless of the distribution of medical service use, costs associated with peanut allergy management and peanut anaphylaxis remain high.

Further contributing to the high costs are comorbidities associated with peanut allergy. With the common coexistence of allergic conditions such as food allergy, asthma, allergic rhinitis, and eczema, ${ }^{22}$ the presence of these comorbidities was unsurprisingly a driver in the high health care costs associated with peanut allergy in this study. In particular, a strong association between asthma and food allergy has been demonstrated in the literature, ${ }^{18,22,23}$ with children with food allergy demonstrating a higher risk of developing asthma (odds ratio $=2.16$ ) in 1 United States retrospective study. ${ }^{18}$ Asthma was observed in more than half of patients with peanut allergy in the current study (54.8\% of privately insured patients; $62.4 \%$ of Medicaid patients), which is consistent with a previous study. ${ }^{40}$ Furthermore, asthma-related costs were significantly higher in patients with peanut allergy, suggesting that the coexistence of both conditions may lead to disease exacerbations requiring additional HRU and subsequent costs. Interestingly, albuterol and prednisolone-medications commonly used to treat asthma-were among the most prescribed drugs contributing to pharmacy costs in Medicaid patients with peanut allergy. Other drugs commonly prescribed included antibiotics, possibly associated with use for other co-morbidities such as atopic dermatitis/eczema and asthma ${ }^{41,42}$; however, additional analyses are required to confirm this finding, because antibiotics are commonly prescribed to children and adolescents, particularly for upper respiratory infections. ${ }^{43-45}$ Despite the presence of comorbidities, even when excluding asthma-related HRU and costs, patients with peanut allergy still incurred significantly more IP, $\mathrm{ED}$, and OP visits and higher health care costs by almost \$2,000 PPPY compared with those without peanut allergy, underscoring the substantial economic burden of peanut allergy that is not solely driven by its frequently associated comorbidities.

In addition to costs, food allergies also negatively affect quality of life in children; increased bullying, missed social activities, separation at mealtimes, and not being allowed to visit friends' homes to play all induce a sense of isolation and anxiety among children with peanut allergy. ${ }^{39}$ Indeed, a cross-sectional study of quality of life in families of children with peanut allergy found that children with peanut allergy had higher separation anxiety and poorer emotional quality of life and psychosocial health than their siblings. ${ }^{20}$ This is consistent with the results of the current study, which estimated higher rates of depression and anxiety among 
children with peanut allergy than those without, demonstrating the far-reaching consequences of peanut allergy beyond economic burden. Of note, mental health-related costs did not differ between the 2 cohorts, likely because they included all types of resource use for any mental healthrelated condition observed in the claims data (not specific to depression or anxiety). This point is particularly relevant among the Medicaid population, which includes a large baseline proportion of individuals with mental illnesses, particularly serious mental illnesses ${ }^{46}$ regardless of peanut allergy status.

\section{LIMITATIONS}

This study should be interpreted in the context of some limitations. The study sample for the cost of care analysis was limited to privately insured and Medicaid-insured individuals from 6 states and their dependents; thus, the generalizability to the overall United States or Medicaid population may be limited, in part by the variability in state-specific Medicaid income eligibility and level of coverage. Claims databases contain diagnostic and procedure codes that are recorded for reimbursement purposes and may be subject to coding errors or data omissions. However, the economic burden in patients with peanut allergy can only be comprehensively quantified using diagnoses in claims databases.

Given that nonallergic food reactions, such as food intolerance, are frequently confused with food allergy (diagnosis of peanut allergy solely) ${ }^{1}$ and that laboratory results from diagnostic test (e.g., allergen-specific serum IgE to peanut test) or severity grades of allergic reaction were not available, patients with a diagnosis of peanut allergy with evidence of reactions to peanuts resulting in HRU were identified based on an algorithm using diagnoses and location of medical services. Although this minimizes the misclassification associated with using peanut allergy ICD-9/10-CM diagnosis codes, it may also result in a sample with an overrepresentation of more severe peanut allergy phenotype. This algorithm to identify allergic reactions to peanuts has not been validated, but we developed a definition that can be used to analyze claims databases that reflect realworld practice.

Additionally, because many patients with peanut allergy also have other food allergies, ${ }^{3}$ patients with reactions to peanuts identified through criterion 2 may have also included those with reactions to other foods. Nevertheless, peanut is the most prevalent food allergy, ${ }^{2,3}$ thereby likely representing the majority of patients identified through criterion 2. Similar to patient selection, asthma-, atopic dermatitis/eczema-, and other food allergy-related costs were identified based on an algorithm using diagnoses and prescriptions.

Finally, the cohort of patients with peanut allergy included a high proportion of patients with asthma. Although asthma exacerbation can be triggered by allergic reactions to peanuts as part of the burden of peanut allergy, a conservative sensitivity analysis was conducted to exclude the HRU and costs directly associated with asthma.

\section{Conclusions}

Despite the practice of peanut avoidance, privately insured and Medicaid-insured pediatric patients aged 4-17 years in the United States with peanut allergy and evidence of allergic reactions triggering HRU had significantly higher comorbidity burdens, HRU, and direct health care costs, regardless of asthma-related costs, compared with those without peanut allergy. Accordingly, there is a significant unmet need for efficient preventive therapies to treat this costly condition.

\section{DISCLOSURES}

This study was funded by Aimmune Therapeutics, a Nestlé Health Science company. The study sponsor was involved in several aspects of the research including the study design, the interpretation of data, the writing of the manuscript, and the decision to submit the manuscript for publication. Yu and Tilles are employees of Aimmune Therapeutics, a Nestlé Health Science company. Robison and Norrett were employees of Aimmune Therapeutics at the time this study was conducted. Blaiss, Meadows, and Hass provided paid consulting services to Aimmune Therapeutics. Guerin and LatremouilleViau are employees of Analysis Group, a consulting company that provided paid consulting services to Aimmune Therapeutics.

Parts of the results were presented at the AMCP Managed Care \& Specialty Pharmacy Annual Meeting held March 25-28, 2019, in San Diego, CA, and at the ISPOR Annual Meeting held May 18-22, 2019, in New Orleans, LA.

\section{ACKNOWLEDGMENTS}

The authors thank Varsha Damle and Christine Birchwood, employees of Aimmune Therapeutics, a Nestlé Health Science company, at the time the study was conducted, for their expertise during the course of this research. Medical writing support was provided by professional medical writers Christine Tam and Loraine Georgy, employees of Analysis Group, which received funding from Aimmune Therapeutics.

\section{REFERENCES}

1. Boyce JA, Assa'ad A, Burks AW, et al. Guidelines for the diagnosis and management of food allergy in the United States: report of the NIAID-sponsored expert panel. J Allergy Clin Immunol. 2010;126 (6 Suppl):S1-58.

2. Gupta RS, Warren CM, Smith BM, et al. The public health impact of parent-reported childhood food allergies in the United States. Pediatrics. 2018;142(6):e20181235. 
3. Gupta RS, Springston EE, Warrier MR, et al. The prevalence, severity, and distribution of childhood food allergy in the United States. Pediatrics. 2011;128(1):e9-17.

4. McGowan EC, Keet CA. Prevalence of self-reported food allergy in the National Health and Nutrition Examination Survey (NHANES) 2007-2010. J Allergy Clin Immunol. 2013;132(5):1216-19 e1215.

5. Sicherer SH, Munoz-Furlong A, Godbold JH, Sampson HA. U.S. prevalence of self-reported peanut, tree nut, and sesame allergy: 11-year follow-up. J Allergy Clin Immunol. 2010;125(6):1322-26.

6. Shaker MS. An economic analysis of a peanut oral immunotherapy study in children. J Allergy Clin Immunol Pract. 2017;5(6):1707-16.

7. Helbling A, Hurni T, Mueller UR, Pichler WJ. Incidence of anaphylaxis with circulatory symptoms: a study over a 3-year period comprising 940,000 inhabitants of the Swiss Canton Bern. Clin Exp Allergy. 2004;34(2):285-90.

8. Klein JS, Yocum MW. Underreporting of anaphylaxis in a community emergency room. J Allergy Clin Immunol. 1995;95(2):637-38.

9. Lin RY, Anderson AS, Shah SN, Nurruzzaman F. Increasing anaphylaxis hospitalizations in the first 2 decades of life: New York State, 19902006. Ann Allergy Asthma Immunol. 2008;101(4):387-93.

10. Dyer AA, Lau CH, Smith TL, Smith BM, Gupta RS. Pediatric emergency department visits and hospitalizations due to food-induced anaphylaxis in Illinois. Ann Allergy Asthma Immunol. 2015;115(1):56-62.

11. Motosue MS, Bellolio MF, Van Houten HK, Shah ND, Campbell RL. Increasing emergency department visits for anaphylaxis, 2005-2014. J Allergy Clin Immunol Pract. 2017;5(1):171-75 e173.

12. Turner PJ, Jerschow E, Umasunthar T, Lin R, Campbell DE, Boyle RJ. Fatal anaphylaxis: mortality rate and risk factors. J Allergy Clin Immunol Pract. 2017;5(5):1169-78.
13. Simons FE, Ardusso LR, Bilo MB, et al. World Allergy Organization guidelines for the assessment and management of anaphylaxis. World Allergy Organ J. 2011;4(2):13-37.

14. Palforzia (peanut [arachis hypogaea] allergen powder-dnfp). Aimmune Therapeutics. January 2020. Accessed December 11, 2020. https://www.palforzia.com/static/pi palforzia.pdf

15. U.S. Department of Agriculture. Allergies and food safety. 2016. Accessed January 7, 2021. https://www.fsis. usda.gov/wps/portal/fsis/topics/ food-safety-education/get-answers/ food-safety-fact-sheets/foodlabeling/allergies-and-food-safety/ allergies-and-food-safety

16. Cummings AJ, Knibb RC, King RM, Lucas JS. The psychosocial impact of food allergy and food hypersensitivity in children, adolescents and their families: a review. Allergy. 2010;65(8):933-45.

17. Flokstra-de Blok BM, Dubois AE, Vlieg-Boerstra BJ, et al. Health-related quality of life of food allergic patients: comparison with the general population and other diseases. Allergy. 2010;65(2):238-44.

18. Hill DA, Grundmeier RW, Ram G, Spergel JM. The epidemiologic characteristics of healthcare provider-diagnosed eczema, asthma, allergic rhinitis, and food allergy in children: a retrospective cohort study. BMC Pediatrics. 2016;16:133.

19. Brew BK, Lundholm C, Gong T, Larsson $\mathrm{H}$, Almqvist C. The familial aggregation of atopic diseases and depression or anxiety in children. Clin Exp Allergy. 2018;48(6):703-11.

20. King RM, Knibb RC, Hourihane JO. Impact of peanut allergy on quality of life, stress and anxiety in the family. Allergy. 2009;64(3):461-68.

21. Primeau MN, Kagan R, Joseph L, et al. The psychological burden of peanut allergy as perceived by adults with peanut allergy and the parents of peanut-allergic children. Clin Exp Allergy. 2000;30(8):1135-43.
22. Foong RX, du Toit G, Fox AT. Asthma, food allergy, and how they relate to each other. Front Pediatr. 2017;5:89.

23. Liu AH, Jaramillo R, Sicherer SH, et al. National prevalence and risk factors for food allergy and relationship to asthma: results from the National Health and Nutrition Examination Survey 2005-2006. J Allergy Clin Immunol. 2010;126(4):798806.e714.

24. Bilaver LA, Kester KM, Smith BM, Gupta RS. Socioeconomic disparities in the economic impact of childhood food allergy. Pediatrics. 2016;137(5):e20153678.

25. Gupta R, Holdford D, Bilaver L, Dyer A, Holl JL, Meltzer D. The economic impact of childhood food allergy in the United States. JAMA Pediatrics. 2013;167(11):1026-31.

26. Miller GF, Coffield E, Leroy Z, Wallin R. Prevalence and costs of five chronic conditions in children. J Sch Nurs. 2016;32(5):357-64.

27. Patel DA, Holdford DA, Edwards E, Carroll NV. Estimating the economic burden of food-induced allergic reactions and anaphylaxis in the United States. J Allergy Clin Immunol. 2011;128(1):110-15 e115.

28. FAIR Health. Food allergy in the United States: recent trends and costs: an analysis of private claims data. November 2017. Accessed December 14, 2020. https:// s3.amazonaws.com/media2.fairhealth. org/whitepaper/asset/Food\%20 Allergy\%20White\%20Paper\%20Final. compressed.pdf

29. Shaker M, Chalil JM, Tran O, et al. Commercial claims costs related to healthcare resource use associated with a diagnosis of peanut allergy. Ann Allergy Asthma Immunol. 2020;124(4):357-65.e1.

30. Bock SA, Atkins FM. The natural history of peanut allergy. J Allergy Clin Immunol. 1989;83(5):900-04.

31. Kaiser Family Foundation. Key issues in children's health coverage. February 15, 2017. Accessed December 11, 2020. https://www. kff.org/medicaid/issue-brief/ key-issues-in-childrens-health-coverage/ 
32. Cohen J. Statistical Power Analysis for the Behavioral Sciences. 2d ed. Hillsdale, NJ: Lawrence Erlbaum Associates Publishers; 1988.

33. Stuart EA, Lee BK, Leacy FP. Prognostic score-based balance measures can be a useful diagnostic for propensity score methods in comparative effectiveness research. J Clin Epidemiol. 2013;66 (8 Suppl):S84-90 e81.

34. Yang D, Dalton JE. A unified approach to measuring the effect size between two groups using SAS. Presented at: SAS Global Forum 2012; Orlando, FL. Accessed December 11, 2020. https://support. sas.com/resources/papers/proceedings12/335-2012.pdf

35. Anvari S, Chokshi NY, Kamili QU, Davis CM. Evolution of guidelines on peanut allergy and peanut introduction in infants: a review. JAMA Pediatrics. 2017;171(1):77-82.

36. Sicherer SH, Burks AW, Sampson HA. Clinical features of acute allergic reactions to peanut and tree nuts in children. Pediatrics. 1998;102(1):e6.
37. Cherkaoui S, Ben-Shoshan M, Alizadehfar R, et al. Accidental exposures to peanut in a large cohort of Canadian children with peanut allergy. Clin Transl Allergy. 2015;5:16.

38. Clark S, Espinola J, Rudders SA, Banerji A, Camargo CA, Jr. Frequency of US emergency department visits for foodrelated acute allergic reactions. J Allergy Clin Immunol. 2011;127(3):682-83.

39. Cannon HE. The economic impact of peanut allergies. Am J Manag Care. 2018;24(19 Suppl):S428-33.

40. Taylor-Black S, Wang J. The prevalence and characteristics of food allergy in urban minority children. Ann Allergy Asthma Immunol. 2012;109(6):431-37.

41. Niebuhr M, Mai U, Kapp A, Werfel T. Antibiotic treatment of cutaneous infections with Staphylococcus aureus in patients with atopic dermatitis: current antimicrobial resistances and susceptibilities. Exp Dermatol. 2008;17(11):953-57.

42. Baan EJ, Janssens HM, Kerckaert T, et al. Antibiotic use in children with asthma: cohort study in UK and Dutch primary care databases. BMJ Open. 2018;8(11):e022979.
43. Grijalva CG, Nuorti JP, Griffin MR. Antibiotic prescription rates for acute respiratory tract infections in US ambulatory settings. JAMA. 2009;302(7):758-66.

44. Kronman MP, Zhou C, Mangione-Smith R. Bacterial prevalence and antimicrobial prescribing trends for acute respiratory tract infections. Pediatrics. 2014;134(4):e956-65.

45. Nyquist AC, Gonzales R, Steiner JF, Sande MA. Antibiotic prescribing for children with colds, upper respiratory tract infections, and bronchitis. JAMA. 1998;279(11):875-77.

46. Kaiser Family Foundation. Facilitating access to mental health services: a look at medicaid, private insurance, and the uninsured. November 27, 2017. Accessed December 11, 2020. https:// www.kff.org/medicaid/fact-sheet/ facilitating-access-to-mental-healthservices-a-look-at-medicaid-privateinsurance-and-the-uninsured/ 